\title{
Trichuris trichiura Infestations in the United Kingdom and Treatment with Difetarsone
}

\author{
D. M. LYNCH, \\ E. A. GREEN, \\ J. A. McFADZEAN, \\ I. M. PUGH \\ $x \mu$
}

British Medical fournal, 1972, 4, 73-76

\section{Summary}

Stool specimens were examined for the parasite Trichuris trichiura from 1,860 patients in 17 hospitals for the mentally subnormal in the U.K. It was found in 10 of these hospitals, and an overall incidence of $13.2 \%$ was recorded. Most cases occurred in the South, where the overall incidence was $36 \cdot 3 \%$.

Difetarsone was used in the treatment of infestations in two hospitals, and proved to be very well tolerated, cure rates of 81 to $88 \%$ being obtained.

\section{Introduction}

One of us (D.M.L.) has observed a high incidence of infestation with the whipworm Trichuris trichiura in a hospital for the mentally subnormal in south-east England over a period of 10 years, though previous attempts at eradication have been largely unsuccessful. Heavy infestations with this parasite had been recorded in a hospital for subnormality in the West of England by Hucker and Schofield (1956) and an incidence of 53\% was recorded by Paine et al. (1960) in a similar hospital in Dorset.

There appeared to be a general belief that the parasite was introduced into the British Isles by immigrant nursing staff after the second world war. Because of the life cycle of the parasite, however, the faecal spread from nurses working in hospitals seems to be almost impossible. In fact, a survey of the literature from the beginning of this century showed that Boycott (1904) found the parasite in $\mathbf{3 8}$ out of $\mathbf{4 8}$ Cornish tin miners. French and Boycott (1905) recorded that $8 \%$ of the inpatients in Guy's Hospital were infested. The same figure was recorded by Still (1927) at necropsies at Great Ormond Street. MansonBahr (1938) recorded a 5\% incidence in all outpatients at Guy's Hospital and had encountered the parasite in rural districts in Kent. Silverston (1962) described two patients from a Cambridgeshire village who had considerable clinical signs. Neighbours and relations were examined (numbers not given) and $40 \%$ of them were shown to harbour the parasite. Hence clearly $T$. trichiura is not a recent importation into the British Isles.

This paper reports the results of a detailed survey of faecal specimens for eggs of $T$. trichiura in two hospitals for subnormality in south-east England, and also a spot survey of similar hospitals throughout the U.K. (see Fig. 2).

A recent review of anthelmintics stated that the treatment of T. trichiura "is very unsatisfactory" (Today's Drugs, 1970). The anthelmintic activity of difetarsone, which has been in use since 1953 as an amoebicide, was recently brought to our attention by three reports describing its value in the treatment of T. trichiura infestations (Junod, 1965; Garin et al., 1970;

Royal Eastern Counties Hospital, Colchester, Essex

D. M. LYNCH, D.P.M., Consultant Psychiatrist

Cell Barnes Hospital, St. Albans, Hertfordshire

E. A. GREEN, M.B., D.P.M., Consultant Psychiatrist

Research Laboratories, May \& Baker Ltd., Dagenham, Essex J. A. McFADZEAN, M.D., F.I.BIol., Chemotherapeutic Research Manager I. M. PUGH, Research Assistant
Nitzulescu et al., 1970), and it was decided to evaluate this compound against $T$. trichiura using the criteria set by the World Health Organization (1964).

The structure of difetarsone, a pentavalent organic arsenical compound, is shown in Fig. 1.

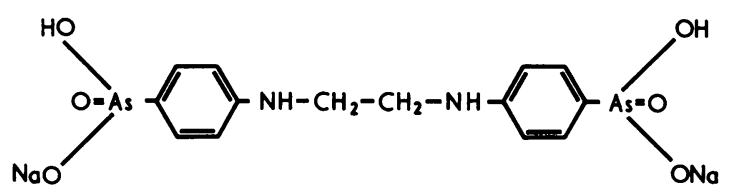

$10 \mathrm{H}_{2} \mathrm{O}$

FIG. 1-Structure of difetarsone.

It is presented as an $0.5 \mathrm{~g}$ tablet and is virtually tasteless. The dose regimen used initially was the standard dosage for amoebiasis of two $0.5 \mathrm{~g}$ tablets twice daily with food for 10 days. Subsequently the same daily dose was given for five days. For children the dose was calculated according to Catzel's formula based on surface area (Catzel, 1966) and was proportionate to age unless the weight of the child was grossly abnormal, when weight alone was used.

\section{Patients and Methods}

The technique of stool examination used was the formol-ether concentration technique described by Allen and Ridley (1970). The deposit obtained by this technique was examined under a 22 by $22 \mathrm{~mm}$ coverglass using a $\times 10$ objective. An arbitrary scoring method was used in the survey: $++++=$ more than 5 eggs per field, $+++=1$ to 5 eggs per field, $++=$ more than 10 eggs per specimen but fewer than 1 egg per field, $+=1$ to 10 eggs per specimen, $0=$ no eggs seen.

In the treatment studies the faeces were not weighed in a pilot trial and the results were recorded only as positive or negative. Subsequently $0.5-\mathrm{g}$ amounts of faeces were weighed and the total number of eggs in the deposit counted under a 22 by 22 mm coverglass using a $\times 10$ objective; the results were expressed as the number of eggs per gramme. Some trichuris eggs were trapped in the layer of debris at the interface of the ether and formol water. This resulted in a slightly low figure being recorded, but this concentration technique is more accurate than the Stoll technique when small numbers of eggs are present. Where the egg counts were high dilutions of the deposit were made.

The pilot trial apart, two specimens of faeces usually at an interval of one week were counted before treatment and the mean figure was taken. After treatment the stools were examined at regular intervals, usually weekly, for at least 30 days and in some cases for up to 60 days.

Hospitals in the Survey.-Specimens from patients in several wards in two hospitals for subnormality, one in Essex and one in Hertfordshire, were examined in detail and repeated specimens taken. For other hospitals a request was made for $\mathbf{1 0 0}$ faecal specimens to be collected, particularly from low-grade patients and children where possible.

Other Specimens.-Two hundred specimens were examined, 100 from adults and 100 from children, from general hospitals in the catchment area for hospitals $1,6,7$, and 8 .

The patients in the clinical trials came from two hospitals. Two studies were made in one hospital in men using a 10-day treatment schedule, the first being a pilot trial which was followed by a detailed trial. Subsequently a trial of a five-day schedule was 
undertaken in the same hospital in men, followed by a trial of the five-day schedule in children of both sexes in another hospital. In some cases the tablets were ground for easy administration to the more severely handicapped patients.

\section{Results of Survey}

\section{HOSPITAL IN ESSEX}

Two wards were examined in detail. These were selected for study as having had the highest incidence of infestation on previous examinations by the hospital laboratory. All the patients were men. The parasitological findings are recorded in Table I. The patients in both wards had been treated at intervals over the preceding years with varying success.

TABLE I-Incidence of $T$. trichiura in Wards Studied in Detail in a Hospital in Essex and a Hospital in Hertfordshire

\begin{tabular}{|c|c|c|c|c|}
\hline $\begin{array}{l}\text { Hospital } 1 \text { (Essex) } \\
\text { Hospital } 2 \text { (Herts) }\end{array}$ & $\cdots$ & $\left\{\begin{array}{l}\text { Ward } \\
\text { R.H. } \\
\text { O.P.P. } \\
6 \\
16 \\
18 \\
23\end{array}\right.$ & $\begin{array}{c}\text { No. Positive/No. Examined } \\
32 / 40 \\
33 / 46 \\
1 / 30 \\
7 / 32 \\
28 / 29 \\
2 / 29\end{array}$ & $\begin{array}{c}\text { \% Positive } \\
80 \\
72 \\
3.3 \\
21.9 \\
96.6 \\
6.9\end{array}$ \\
\hline
\end{tabular}

\section{HOSPITAL IN HERTFORDSHIRE}

Four wards were examined in detail. The patients were mainly children (age range 1-20 years) and they had not previously received treatment for trichuris infestation. These findings are also recorded in Table $I$.

\section{HOSPITALS THROUGHOUT THE U.K.}

Between 70 and 100 specimens were obtained from 14 hospitals (Fig. 2). Altogether 404 specimens were examined from hospital 8. So far as can be determined treatment had been given in only one hospital (No. 6). The incidence of trichurdis infestation in these hospitals ranged from 0 to $55.6 \%$ (Table II). In general the highest incidence was in southern England, with the intensity diminishing from south to north. In fact only three positive specimens from two hospitals were recorded above a line

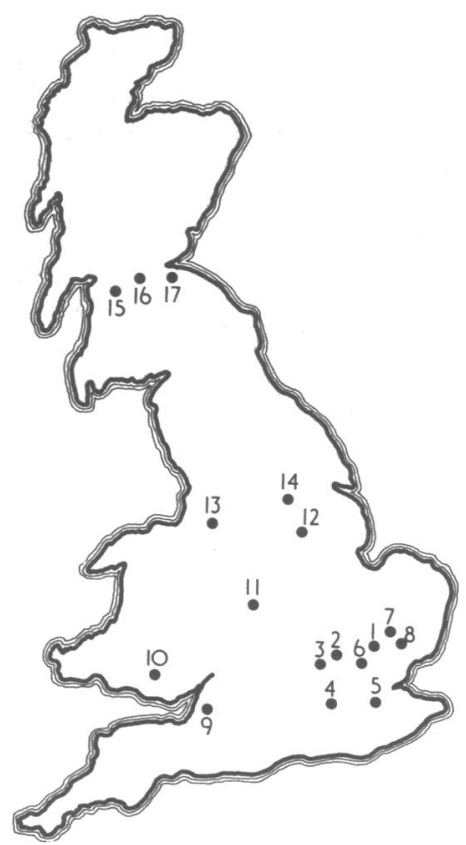

FIG. 2-Map showing the location and reference numbers of hospitals surveyed.
TABLE II-Incidence of $T$. trichiura in Hospitals in the U.K.

\begin{tabular}{c|c|c|c}
\hline Hospital No. & $\begin{array}{c}\text { No. Positive/No. } \\
\text { Examined }\end{array}$ & $\%$ Positive & $\begin{array}{c}\text { No. of Wards } \\
\text { Positive/No. of } \\
\text { Wards Examined }\end{array}$ \\
\hline 3 & $15 / 88$ & $17 \cdot 1$ & $4 / 5$ \\
4 & $1 / 70$ & 1.4 & $1 / 13$ \\
5 & $50 / 96$ & $52 \cdot 1$ & $7 / 7$ \\
6 & $20 / 96$ & $2 \cdot 8$ & $7 / 19$ \\
7 & $1 / 78$ & $1 \cdot 3$ & $1 / 4$ \\
8 & $3 / 404$ & $0 \cdot 7$ & $3 / 11$ \\
9 & $9 / 94$ & 55.6 & $8 / 24$ \\
10 & $40 / 72$ & 0.6 & $0 / 5$ \\
11 & $0 / 75$ & $2 \cdot 0$ & $1 / 10$ \\
12 & $2 / 100$ & 0 & $1 / 10$ \\
13 & $1 / 97$ & 0 & $0 / 13$ \\
14 & $0 / 96$ & 0 & $0 / 6$ \\
15 & $0 / 96$ & 0 & $0 / 9$ \\
16 & $0 / 100$ & $0 / 92$ &
\end{tabular}

drawn between Fishguard and Harwich. No parasites were found in the specimens from the three Scottish hospitals.

The total number of specimens examined from all the hospitals was 1,860. Eggs were found in 245 of these, giving an overall percentage positive of $13 \cdot 2 \%$. Consideration of the data from the seven hospitals where the parasite appeared to be prevalent-namely, hospitals $1,2,3,5,6,9$, and 10-showed that out of a total of 652 specimens examined $237(36.3 \%)$ were found to be positive. Data on the sex of all but six of these patients were available. Out of 471 specimens from males examined $201(42.7 \%)$ were found to be positive, and of the 175 specimens from females examined $31(17 \cdot 7 \%)$ were positive.

While more males were examined than females clearly the parasite is more common in males and the peak incidence in both appears to be from 11 to 30 years (Fig. 3). The numbers in the $70+$ age group are too small to place much significance on the rise in incidence in men. The distribution of densities of infestation by age and by sex in terms of the arbitrary scale is shown in Fig. 4.

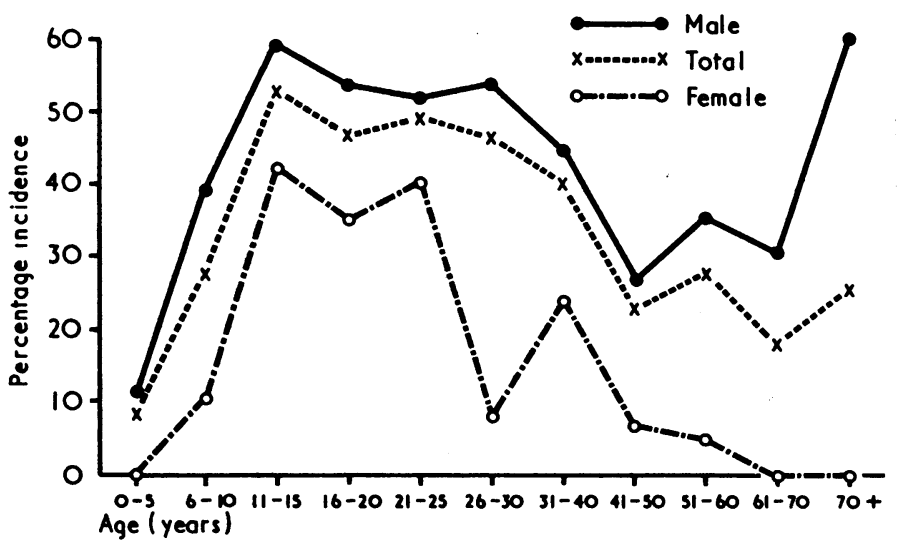

FIG. 3-Incidence of trichuris infestation by age and sex in hospitals where parasite was prevalent.

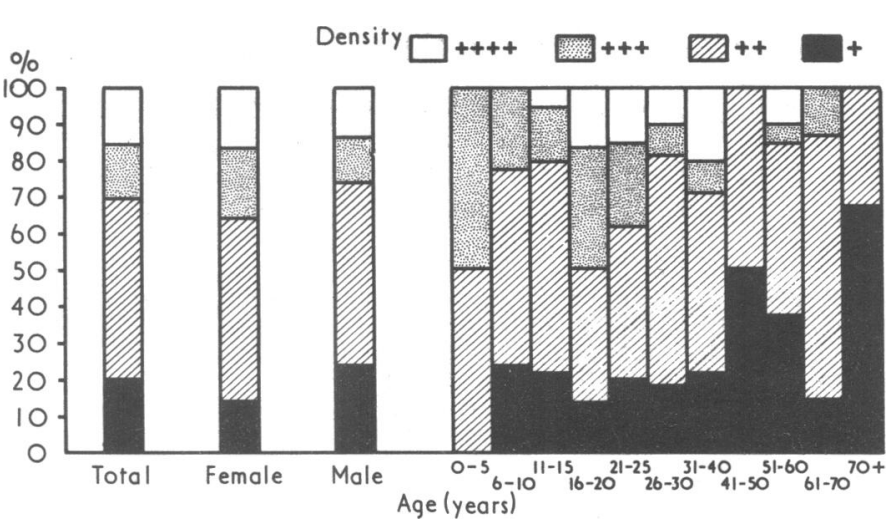

FIG. 4-Distribution of densities of infestation by sex and age in hospitals where parasite was prevalent. For density scale see text. 
Egg counts were undertaken on duplicate samples from 74 of the patients from hospitals 1 and 2 using the Allen and Ridley technique with $0.5 \mathrm{~g}$ of faeces. The means of these egg counts are grouped in Table III.

TABLE III-Details of Densities of Egg Counts of T. trichiura in 74 Patients from Hospitals 1 and 2

\begin{tabular}{l|c|c|c|c|c}
\hline $\begin{array}{l}\text { Mean No. of eggs/g } \\
\begin{array}{l}\text { No. of patients } \\
\text { (\% of total) }\end{array}\end{array}$ & $\leqslant 10$ & -100 & $-1,000$ & $-10,000$ & $-100,000$ \\
\hline
\end{tabular}

Other Specimens. - No trichuris eggs were found in the 200 specimens examined from general hospitals. This was an extremely small number, however, as difficulties were encountered in obtaining specimens, and no conclusions may be drawn from the absence of eggs.

Other Parasites.-Other helminth and protozoan parasites which were found were recorded and their prevalence will be the subject of a separate report.

\section{CLINICAL TRIALS OF DIFETARSONE}

The criterion of cure was three consecutive negative stool specimens, the last specimen being taken not earlier than 30 days after completion of treatment.

Ten Days' Treatment.-In a pilot trial 32 patients were treated and $28(88 \%)$ were cured.

Main Trials.-Out of 59 cases studied $48(81 \%)$ can be assessed as cured (Table IV). Of the 11 failures eight showed large reductions in egg output and three showed no change.

TABLE IV-T. trichiura Egg Counts Before and After 10 Days' Treatment with Difetarsone

\begin{tabular}{|c|c|c|c|c|}
\hline $\begin{array}{l}\text { Mean No. of } \\
\text { Eggs/g Before } \\
\text { Treatment }\end{array}$ & $\mid \begin{array}{l}\text { No. of } \\
\text { Patients }\end{array}$ & $\begin{array}{l}\text { No. }(\%) \\
\text { Cured }\end{array}$ & $\begin{array}{c}\text { Failures } \\
\left(\frac{\text { Highest Count After Treatment }}{\text { Mean Count Before Treatment }}\right)\end{array}$ & $\begin{array}{c}\text { Minimum } \\
\text { Reduction of } \\
\text { Eggs/g } \\
(\%)\end{array}$ \\
\hline $\begin{aligned} \geqslant 20,000 \\
10,000-19,999 \\
1,000-9,999 \\
<1,000\end{aligned}$ & $\begin{array}{r}2 \\
3 \\
5 \\
49\end{array}$ & $\begin{array}{c}2(100) \\
0 \\
3(60) \\
43(88)\end{array}$ & $\begin{array}{l}2 / 14,220,12 / 14,180,88 / 10,091 \\
42 / 9,973,70 / 3,736,2286,8 / 9 \\
24 / 761,20 / 494,22 / 286,8 / 9 \\
46 / 52,120 / 106\end{array}$ & $\begin{array}{l}99 \cdot 9,99 \cdot 9,99 \cdot 1 \\
99 \cdot 5,98 \cdot 1,9 \cdot 1 \\
96 \cdot 9,95 \cdot 9,92 \cdot 3 \\
0,0,0\end{array}$ \\
\hline
\end{tabular}

Total cure rate $48 / 59(81 \%)$.

Five Days' Treatment.-After five days' treatment eggs were still being passed up to 19-25 days in some patients who subsequently had three negative stool examinations (Table V.) The cure rate in this trial was 35 out of $41(85 \%)$. The six failures showed substantial reductions in egg counts. One patient was passing adult worms on day 12 .

TABLE v-T. trichiura Egg Counts Before and After Five Days' Treatment with Difetarsone

\begin{tabular}{c|c|c|c|c}
\hline $\begin{array}{c}\text { Mean No. } \\
\text { of Eggs/g Before } \\
\text { Treatment }\end{array}$ & $\begin{array}{c}\text { No. of } \\
\text { Patients }\end{array}$ & $\begin{array}{c}\text { No. (\%) } \\
\text { Cured }\end{array}$ & $\begin{array}{c}\text { Failures } \\
\text { (Highest Count After Treatment } \\
\text { Mean Count Before Treatment }\end{array}$ & $\begin{array}{c}\text { Minimum } \\
\text { Reduction } \\
\text { of Eggs/g } \\
(\%)\end{array}$ \\
\hline$\geqslant 20,000$ & 1 & 0 & $156 / 26,400$ & 6 \\
$10,000-19,999$ & 1 & 0 & $6 / 14,050$ & $99 \cdot 4$ \\
$1,000-9,999$ & 15 & $13(87)$ & $18 / 5,440,34 / 1,020$ & 99.9 \\
$<1,000$ & 24 & $22(92)$ & $2 / 570,4 / 382$ & $99.7,96 \cdot 7$ \\
$99 \cdot 7,99 \cdot 0$
\end{tabular}

Total cure rate $35 / 41(85 \%)$.

Cysts of Entamoeba histolytica were observed in pretreatment stool specimens from 52 of the patients in the trial of the 10-day course. During the periods of observation after treatment no cysts of $E$. histolytica were excreted.

Side Effects. - No vomiting or other side effects were observed with either dosage schedule.

\section{Discussion}

T. trichiura has been endemic in this country for a good many years and is not a recent importation by immigrant nursing staff from endemic areas. This fact is reinforced by consideration of the life cycle of the parasite, whereby the eggs passed in the faeces require to be incubated outside the body for a variable period of time (in weeks) to mature. It seems most unlikely that this could occur with infested nursing staff in a hospital.

It is clear too from this survey that the parasite is a common finding in many hospitals for the mentally subnormal. In general the most striking feature was the prevalence of the parasite in southern England and Wales, with little incidence above a line drawn between Fishguard and Harwich. An obvious possible explanation of this observation is the high temperature in the south; the higher the temperature the shorter the incubation period of the eggs.

A second possible explanation is the relationship with pigs. Beer (1971) showed that $T$. suis may infest man. In fact an incidental infestation of man with $T$. suis took place in his laboratory (Financial Times, 1971). Information was obtained from the hospitals surveyed regarding pig-keeping in the hospital grounds and the use of pig manure in the hospital gardens. All of the hospitals where the parasite was found to be prevalent either currently kept pigs or had kept pigs in the past. Of the hospitals where the parasite was absent or rare only one currently kept pigs, although four others had done so in the past. Pig manure was being used in the grounds of three hospitals where the parasite was found and in two where it was not found. Pig manure had been most commonly used in the past in the hospitals which currently did not have cases or trichuris infestation.

The data on the numbers of pigs in each county (Ministry of Agriculture, Fisheries and Food, 1971) did not correlate with the incidence of trichuris infestation in hospitals in the corresponding county. Eggs from a hospital not included in the present survey were examined to determine their measurements. In this hospital there was a high incidence of trichuris eggs in children's wards built on ground which had 13 years previously been used for keeping pigs. R. J. S. Beer (personal communication, 1971) reported that the eggs conformed to the measurements of $T$. trichiura rather than to those of $T$. suis. Hence it seems unlikely that the human infestations in these hospitals came from pigs.

In hospital 1 examinations for eggs of trichuris have been made intermittently since 1967 in and around the hospital buildings. Inside they have been found virtually from floor to ceiling - for example, behind radiators, on fanlights, and on high window ledges. Outside they have been recorded on tarmac, in soil, and around swings. There was no evidence found of the eggs maturing inside the buildings, but the parasite has been found in non-ambulant patients who did not have contact with the ground. The possibility of infestation being contracted inside the buildings cannot be ruled out.

This parasite, like many other intestinal parasites, lends itself to transmission in hospitals for subnormality where double incontinence is common and where foreign material including earth is commonly eaten. There was some evidence of correlation of infestation with degree of subnormality in the two hospitals examined in detail.

Stool specimens from 29 members of the nursing and domestic staff were examined in a hospital where trichuris was common. Specimens from two of the nursing staff were found to be positive. One of these was from an immigrant who could have become infested overseas but the other was from a person who had not been out of this country. It seems likely that this infestation had been acquired in the hospital. It was not possible to determine in the patients under observation possible signs and symptoms of infestation with trichuris. Anaemia and diarrhoea were possible sequelae but there was no record of appendicitis due to blockage of the lumen by the parasite or of the other extreme sign of rectal prolapse.

The 200 specimens examined from general hospitals showed 
no eggs of trichuris. The only information on the occurrence of this parasite in the U.K. is from the returns made to the Public Health Laboratory Service. The number reported in 1969 was 1,218 and in 1970 was 1,132 (P.H.L.S., personal communication, 1971). However, the examination of stool specimens for helminth ova is not a routine procedure in many laboratories.

A survey of intestinal parasites in 3,855 immigrant children (Thompson et al. 1972) showed that about $14 \%$ harboured $T$. trichiura. In children from Hong Kong and the West Indies the incidences were over $70 \%$.

The cure rates obtained in the trials of difetarsone ranging from 81 to $88 \%$ were slightly lower than the 96,96 , and $94 \%$ obtained respectively by Junod (1965), Garin et al. (1970), and Nitzulescu et al. (1970) using 10-day schedules. However, the method of examination of faeces used in the present study was more stringent. There was little difference in the final cure rates after a 10-day dosage schedule or a five-day schedule. It appeared, however, that the five-day schedule took longer to effect a cure in a number of patients than did the 10-day schedule.

Adult worms were observed in only one patient, a child, and these were being passed 12 days after the completion of five days' treatment. It appears that there is little to be gained in re-examining stools earlier than at least two weeks after the completion of treatment. Difetarsone was very well tolerated and no side effects were observed.

Where the infestation is widespread or has been established in the hospital for some time potentially infective eggs will be found contaminating the grounds and buildings for lengthy periods, probably in years. A further point is that patients may be harbouring immature worms which may not be affected by the drug. Hence the design of the initial treatment regimen for the hospital and the timing of subsequent retreatment have to be considered carefully.

The examination of stool specimens from every patient by a concentration technique would be very time-consuming and is not a practical proposition for most hospitals. Sample surveys of wards would give an indication of the incidence in a hospital, and where this is high it is probably reasonable with such a non-toxic drug to treat all of the patients initially. Because of the problem of reinfestation and the treatment failures retreatment appears to be necessary, and treatments at six monthly intervals over a period of five years may be necessary to eliminate the parasite from a heavily infested hospital.

We are grateful to the medical superintendents and consultants of the hospitals involved for their co-operation. We are also grateful to the nursing staff of these hospitals for the collection of the specimens, and to the laboratory staff of the Royal Eastern Counties Hospital for permission to quote some of their findings.

\section{References}

Allen, A. V. H., and Ridley, D. S. (1970). Fournal of Clinical Pathology, 23, Beer, R. J. S. (1971). British Medical fournal, 2, 44.

Boycott, A. E. (1904). Fournal of Hygiene, 4, 437.

Catzel, P. (1966). Paediatric Prescriber, 3rd edn. Oxford, Blackwell Scientific. Financial Times, 1971, 3 August, p. 4.

French, H. S., and Boycott, A. E. (1905). Fournal of Hygiene, 5, 274. Garin, J. P., Despeignes, J., Woehrle, R., and Ambroise-Thomas, P. (1970) Bulletin de la Societe de Pathologie Exotique et de Ses Filiales, 63, 94

Hucker, A. G., and Schofield, F. D. (1956). British Medical fournal, 2, 1159. Junod, C. (1965). Bulletin de la Societe de Pathologie Exotique et de Ses Filiales, 58, 653 .

Manson-Bahr, P. H. (1938). British Encyclopaedia of Medical Practice, vol. 9, p. 133. London, Butterworths.

Ministry of Agriculture, Fisheries and Food (1971). Agricultural Statistics 1968-69. London, H.M.S.O.

Nitzulescu, V. et al. (1970). Bulletin de la Societe de Pathologie Exotique et de Ses Filiales, 63, 251.

Paine, D. H. D., Lower, E. S., and Cooper, T. V. (1960). British Medical Fournal, 1, 770 .

Silverston, N. A. (1962). British Medical fournal, 2, 1726.

Still, G. F. (1927). Common Disorders of Childhood, 5th edn., p. 370 . London, Oxford University Press.

Thompson, R. G., Hutchinson, J. G. P., and Johnston, N. M. (1972). British Medical fournal, 1, 591 .

Today's Drugs (1970). British Medical fournal, 1, 738.

World Health Organization (1964). Technical Report Series, No. 277, p. 65.

\title{
Heart Failure and Neonatal Hypocalcaemia
}

\author{
O. TROUGHTON, S. P. SINGH
}

British Medical fournal, 1972, 4, 76-79

\section{Summary}

Six infants had congestive heart failure for which no cause could be found apart from a low serum calcium. All except one recovered completely and had normal chest $x$-ray appearances and E.C.G.s on discharge from hospital. Necropsy on the infant who died showed engorgement and dilation of the right side of the heart and a small ductus but no other abnormalities. It is suggested that hypocalcaemia should be considered as a possible cause of heart failure in infants, especially when oedema is prominent.

\section{Introduction}

Although calcium plays a major part in the metabolism of the myocardium serious cardiovascular disease due to its de-

Children's Hospital, Birmingham 16

O. TROUGHTON, M.R.C.P., D.C.H., Senior Registrar

S. P. SINGH, M.B., P.R.C.P., Consultant Cardiologist ficiency has been reported only rarely. Hegglin (1939-40) described heart failure associated with hypocalcaemia in a woman aged 51 years. This failed to respond to digitalis and diuretics but improved promptly when she was given AT 10 (dihydrotachysterol). Dodd and Rapoport (1949) stated that cardiac manifestations-oedema, systolic murmurs, change in rate-could occur in hypocalcaemia, though in the presence of the postacidotic state when other electrolyte disturbances were also present. Schulman and Ratner (1955) reported the case of a 12-year-old girl with chronic hypoparathyroidism whose cardiac decompensation improved with rises in serum calcium. The heart was normal three months after treatment. Weill et al. (1967) reported on a 9-year-old child with idiopathic hypoparathyroidism who had cardiac enlargement which regressed over a period of three months on calcium and vitamin $\mathrm{D}$.

So far as infants are concerned actual heart failure has been reported only twice. Edge (1963) described three infants with congestive failure associated with hypocalcaemia, and Najjer et al. (1967) reported the case of an 18-month-old child with rickets and heart failure. We present the cases of six infants who had congestive heart failure for which no cause could be found and in whom the serum calcium was low. The cause of the heart failure was not definitely proved to be hypo- 